\section{Aortic Graft Infection Secondary to latrogenic Transcolonic Graft Malposition}

\section{Abstract}

Context: Aortic graft infections are a rare but devastating complication of aortic revascularization. Often infections occur due to contamination at the time of surgery. latrogenic misplacement of the limbs of an aortobifemoral graft is exceedingly rare, and principles of evaluation and treatment are not well defined. We report two cases of aortobifemoral bypass graft malposition through the colon.

Case report: Case 1 is a 54 year old male who underwent aortobifemoral bypass grafting for acute limb ischemia. He had previously undergone a partial sigmoid colectomy for diverticulitis. Approximately six months after vascular surgery, he presented with an occult graft infection. Preoperative imaging and intraoperative findings were consistent with graft placement through the sigmoid colon. Case 2 is a 60 year old male who underwent aorto bifemoral bypass grafting due to a nonhealing wound after toe amputation. His postoperative course was complicated by pneumonia, bacteremia thought to be secondary to the pneumonia, general malaise, and persistent fevers. Approximately ten weeks after the vascular surgery, he presented with imaging and intraoperative findings of graft malposition through the cecum.

Conclusions: Aortic graft infection is usually caused by surgical contamination, and presents as an indolent infection. Case 1 presented as such; Case 2 presented more acutely. Both grafts were iatrogenically misplaced through the colon at the index operation. The patients underwent extra-anatomic bypass and graft explantation and subsequently recovered.

Keywords: Blood vessel prosthesis implantation/Adverse effects; Blood vessel prosthesis implantation/Instrumentation; Blood vessel prosthesis implantation/ Mortality; Peripheral vascular disease; Vascular prostheses

Received: October 16, 2017; Accepted: October 24, 2017; Published: October 30,

\author{
Jacqueline J Blank', \\ Abby E Rothstein', \\ Cheong Jun Lee², \\ Michael J Malinowski², \\ Brian D Lewis', \\ Timothy J Ridolfi' and \\ Mary F Otterson ${ }^{1 *}$
}

\section{Department of Surgery, Division of Colorectal Surgery, Medical College of Wisconsin, Milwaukee, WI, USA \\ 2 Department of Surgery, Division of Vascular Surgery, Medical College of Wisconsin, Milwaukee, WI, USA}

\section{*Corresponding author: Mary F Otterson \\ = motterso@mcw.edu}

Department of Surgery, Division of Colorectal Surgery, Medical College of Wisconsin, $9200 \mathrm{~W}$ Wisconsin Ave, Milwaukee, WI 53226, USA.

Tel: $414-805-5733$

Fax: $805-8115$

Citation: Blank JJ, Rothstein AE, Lee CJ, Malinowski MJ, Lewis BD, et al. (2017) Aortic Graft Infection Secondary to latrogenic Transcolonic Graft Malposition. J Vasc Endovasc Surg. Vol. 2 No.4:30 2017

\section{Introduction}

Aortic Graft Infection (AGI) is rare and may be a devastating and costly complication of both open and endovascular aortic surgery. The presentation of patients with AGI varies depending on the interval from surgery. Presentation within four weeks of the index surgery is classified as early AGI, and is usually characterized by more severe systemic symptoms of sepsis than those that present greater than four weeks from the index operation [1]. One must have a high index of suspicion to diagnose $A G I$, as these infections are rare and may mimic other more common complications. Commonly, the causative organisms are indolent skin flora, such as Staph epidermidis, due to contamination at the time of surgery [2]. The treatment of choice for aortic graft infection includes broad-spectrum antibiotic coverage and graft explanation with in situ or extra-anatomic bypass to preserve distal perfusion. Due to the increased use of endoluminal techniques for revascularization, open procedures for aortoiliac occlusive disease are utilized less often and are frequently more complex. Resident and fellow training in such procedures is now less common, and therefore surgeons trained in the endovascular era may feel less comfortable with reconstruction [3]. We present two cases of infected aortic grafts secondary to iatrogenic malposition through the colon during open aortic repair. 


\section{Case Report}

\section{Case 1}

A 54-year-old male with a history of hypertension, hyperlipidemia, asthma, and diverticulitis underwent emergent Hartmann procedure and subsequent reversal for perforated diverticulitis. One year later, he developed acute limb ischemia for which he underwent an open aortobifemoral bypass. The acuity of this presentation resulted in a limited preoperative vascular evaluation. Six months after aortobifemoral bypass surgery; he presented to our institution with fever and left leg pain for three days. The patient was hemodynamically normal, with no external stigmata of infection. Pulse exam was notable for a strong right femoral pulse and a palpable but weak left femoral pulse, as well as palpable right pedal pulses and left pedal signals by ultrasound only. Laboratory evaluation revealed leukocytosis to 18,400 cells $/ \mu \mathrm{L}$ (reference range $3,900-11,200$ cells $/ \mu \mathrm{L}$ ), blood cultures were negative, and Erythrocyte Sedimentation Rate and C-Reactive Protein (ESR and CRP, respectively) were not obtained (Table 1). Imaging demonstrated perigraft gas and phlegmon in the left lower quadrant, involving both the remnant sigmoid colon and left limb of the aortobifemoral bypass graft (Figure 1). The differential diagnosis included residual diverticular disease affecting the left limb of the graft and primary graft infection.
The patient first underwent a left axillary-femoral bypass with ePTFE graft and was admitted to the Intensive Care Unit (ICU) for stabilization and preparation for the second stage of the operation. In the interim, the patient tolerated a general diet, but overall nutrition remained poor with an albumin of $2.0 \mathrm{~g} /$ $\mathrm{dL}$ (reference range 3.5-5.2 g/dL). After mechanical and oral antibiotic bowel preparation, the patient was taken for abdominal exploration with graft explantation, as well as primary repair of a previously existing ventral hernia. During this operation, it was noted that the left limb of the aortobifemoral graft traversed the sigmoid colon in a "through and through" fashion (Figure 2). The sigmoid colon and graft were excised en bloc. Graft cultures grew Staphylococcus epidermidis, Streptococcus anginosus, and Actinomyces odontolyticus, which represent common skin, oropharyngeal, and gastrointestinal bacteria [4-6]. The patient's postoperative course was complicated by a colonic anastomotic leak, which was repaired primarily and protected with a temporary diverting loop ileostomy. The patient was discharged on six weeks of intravenous (IV) tigecycline, followed by six weeks of oral doxycycline. Postoperative inflammatory markers decreased as expected. One year later, the patient reported normal bowel function and no further lower extremity perfusion deficits.

Table 1 Preoperative and postoperative laboratory parameters of patients in Case 1 and Case 2. Albumin (institutional reference range 3.5-5.2 g/dL), WBC=White Blood Cell count (3,900-11,200 cells/ $\mu \mathrm{L}), \mathrm{ESR}=$ Erythrocyte Sedimentation Rate $(0-19 \mathrm{~mm} / \mathrm{hour})$, CRP=C-Reactive Protein (0.0-0.5 mg/ dL), Glycosylated Hemoglobin (3.9-6.1\%). Blank spaces represent unmeasured laboratory values.

\begin{tabular}{|c|c|c|c|c|}
\hline & After initial aortic surgery & $\begin{array}{c}\text { Time of } \\
\text { Revascularization }\end{array}$ & Time of Graft Explantation & $\begin{array}{l}1 \text { month after } \\
\text { Explantation }\end{array}$ \\
\hline \multicolumn{5}{|c|}{ Case 1} \\
\hline BMI $(\mathrm{kg} / \mathrm{m} 2)$ & 28.79 & & 28.43 & 24.96 \\
\hline WBC (cells $/ \mu \mathrm{L}$ ) & Average 11.63 (9.9-12.6) & 18.7 & 12.1 & 8.5 \\
\hline $\mathrm{ESR}(\mathrm{mm} / \mathrm{hr})$ & & & & 25 \\
\hline $\mathrm{CRP}(\mathrm{mg} / \mathrm{dL})$ & & & & 4.3 \\
\hline Albumin (g/dL) & & & 2 & 2.4 \\
\hline \multicolumn{5}{|l|}{ Glycosylated Hemoglobin (\%) } \\
\hline Blood cultures & & Negative & Negative & \\
\hline Graft cultures & & & $\begin{array}{l}\text { Staphylococcus epidermidis, Streptococcus } \\
\text { anginosus, Actinomyces odontolyticus }\end{array}$ & \\
\hline Bowel preparation & & & $\begin{array}{l}\text { Oral Neomycin, mechanical bowel } \\
\text { preparation (polyethylene glycol) }\end{array}$ & \\
\hline \multicolumn{5}{|c|}{ Case 2} \\
\hline BMI $(\mathrm{kg} / \mathrm{m} 2)$ & 27.23 & 21.3 & 21.3 & 20.49 \\
\hline WBC (cells $/ \mu \mathrm{L}$ ) & Average 14.3 (9.3-18.9) & 16 & 14.9 & 10.6 \\
\hline $\mathrm{ESR}(\mathrm{mm} / \mathrm{hr})$ & & 106 & & 40 \\
\hline $\mathrm{CRP}(\mathrm{mg} / \mathrm{dL})$ & 134.9 & 238.8 & & 3.6 \\
\hline Albumin (g/dL) & & 2.6 & & 3 \\
\hline \multicolumn{2}{|l|}{ Glycosylated Hemoglobin (\%) } & 12.5 & & 6.3 \\
\hline Blood cultures & $\begin{array}{c}\text { Klebsiella pneumoniae, } \\
\text { Enterococcus, Citrobacter } \\
\text { amalonaticus, Candida } \\
\text { glabrata, Psuedomonas } \\
\text { aeruginosa }\end{array}$ & Negative & Negative & \\
\hline Graft cultures & & & Candida Glabrata, Pseudomonas aeruginosa & \\
\hline Bowel preparation & & & $\begin{array}{l}\text { Partial mechanical bowel preparation } \\
\text { (polyethylene glycol) }\end{array}$ & \\
\hline
\end{tabular}



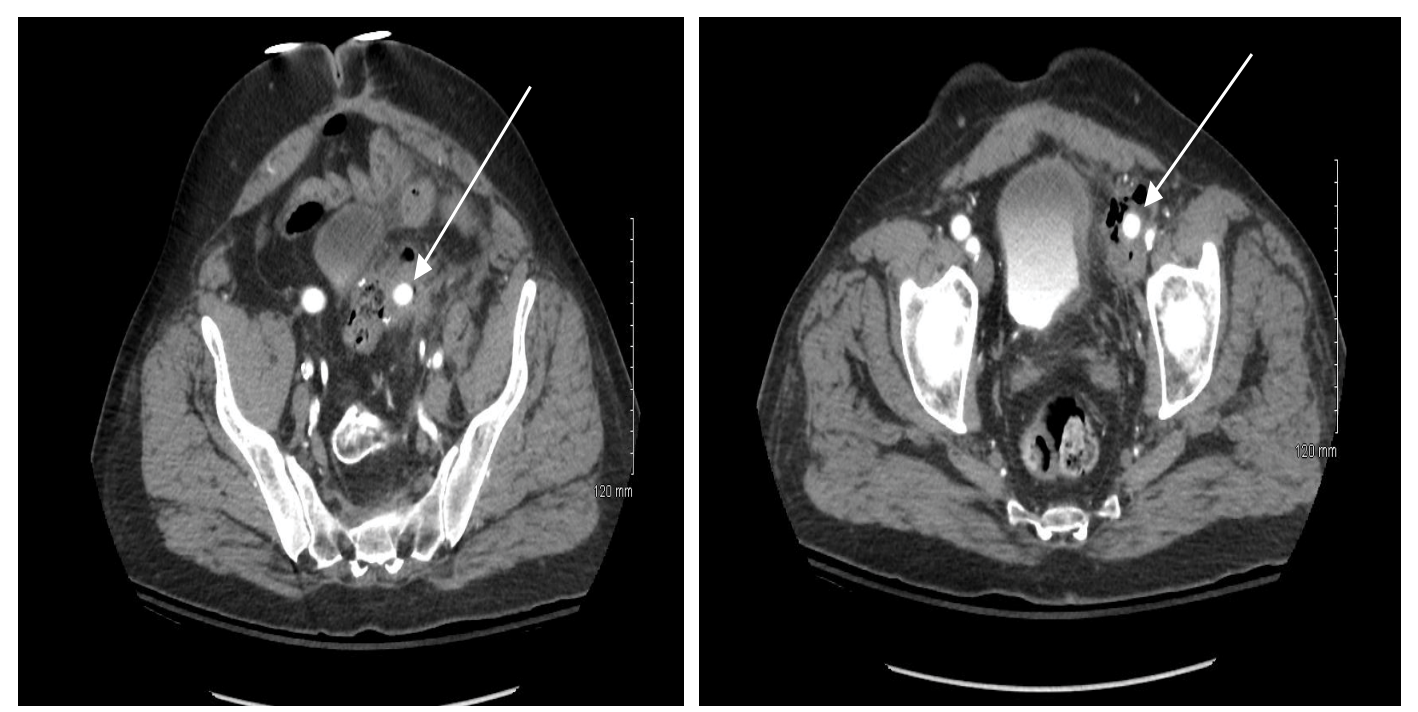

Figure 1 Left limb of the aortic graft (write arrows) traversing the sigmoid colon demonstrated on two successive slices of a CT-Angiogram.

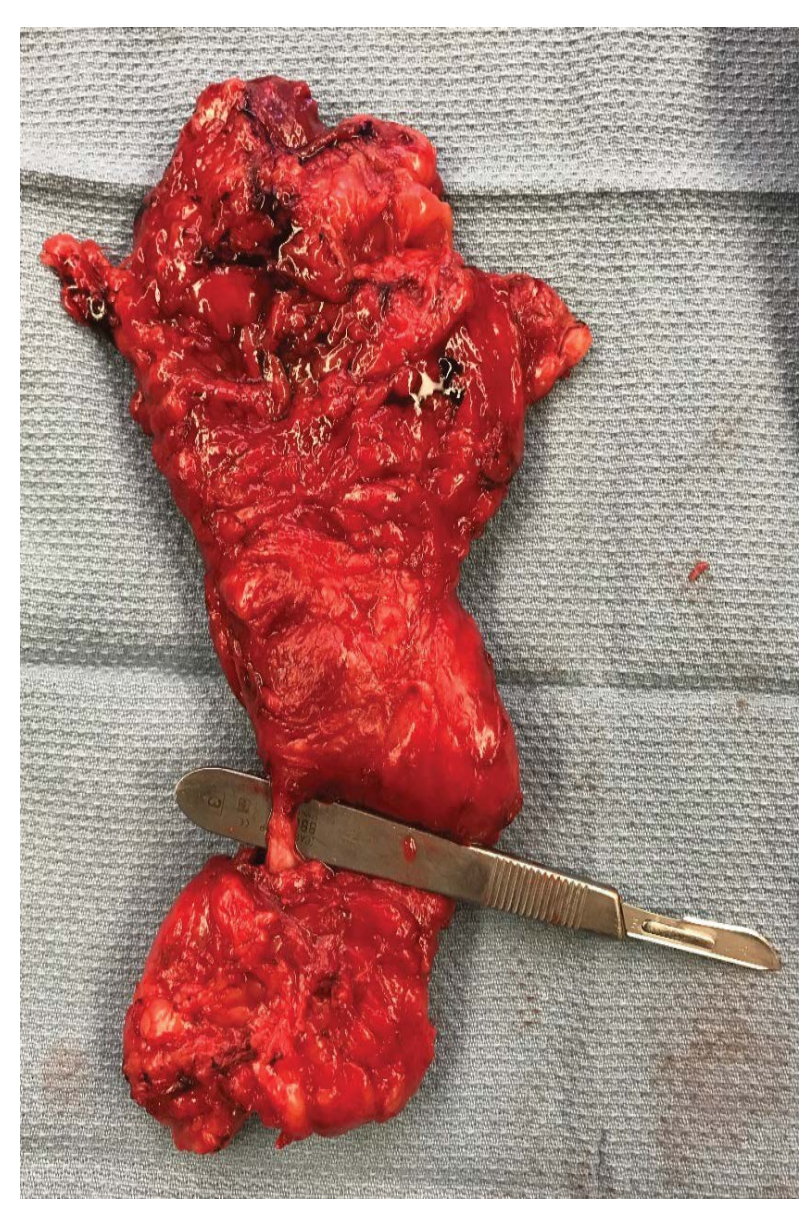

Figure 2 Left limb of aortic graft penetrating the sigmoid colon. Proximal colon is at the top, distal colon is at the bottom of picture.

\section{Case 2}

A 60-year-old male with a history of peripheral vascular disease, Type 2 Diabetes Mellitus (DM2) (Hemoglobin A1c = $12.5 \%$, reference range $3.9-6.1 \%$ ), and hypertension presented to his podiatrist with a right great toe ulcer and underlying osteomyelitis. He underwent right great toe amputation, which failed to heal. Vascular evaluation demonstrated extensive and widespread disease for which he underwent aortobifemoral bypass. The patient was discharged on six weeks of oral doxycycline, metronidazole, and cefadroxil due to his recent history of osteomyelitis.

Approximately two weeks postoperatively, the patient presented with fevers and malaise. His operative wounds were healing appropriately without signs of infection. Laboratory evaluation revealed Klebsiella pneumoniae and Enterococcus bacteremia; CRP was $134.9 \mathrm{mg} / \mathrm{dL}$ (reference range $0.0-0.5 \mathrm{mg} / \mathrm{dL}$ ) and ESR was not measured (Table 1). Imaging demonstrated a left lower lobe lung consolidation as well as perigraft fluid and gas in the right lower quadrant (Figure 3a-c). The right lower quadrant findings were presumed to be normal postoperative changes, and thus the patient was treated for pneumonia. He was discharged with six weeks of IV ceftriaxone and daptomycin, as well as oral levofloxacin. Approximately four weeks postoperatively, he was again evaluated for fevers and found to have Candida albicans fungemia, and began oral fluconazole treatment.

The patient was seen in follow-up approximately 8 weeks after his aortobifemoral bypass and described persistent fevers and malaise in the interim. White blood cell count at the time was 23,200 cells/ $\mu \mathrm{L}, \mathrm{CRP}$ was $238.8 \mathrm{mg} / \mathrm{dL}$, and ESR was 106 $\mathrm{mm} /$ hour (reference range 0-19 $\mathrm{mm} /$ hour). A computed tomography (CT) scan again demonstrated perigraft fluid and gas, still felt to be postoperative changes. Subsequent imaging 10 weeks postoperatively demonstrated perigraft phlegmon with air pockets in the right lower quadrant, and the patient was ultimately diagnosed with aortic graft infection (Figure 3d-f).

The patient was transferred to our institution and underwent 
a right axillary-femoral bifemoral bypass with PTFE graft and staged graft explantation. Prior to the colon resection, the patient tolerated a partial polyethylene glycol bowel preparation, but did not receive antibiotic bowel preparation. During the second procedure, it was noted that the right limb of the aortobifemoral graft traversed the cecum (Figure 4). The graft and cecum were resected en bloc; intraoperative graft cultures grew Pseudomonas aeruginosa and Candida glabrata. The patient's postoperative
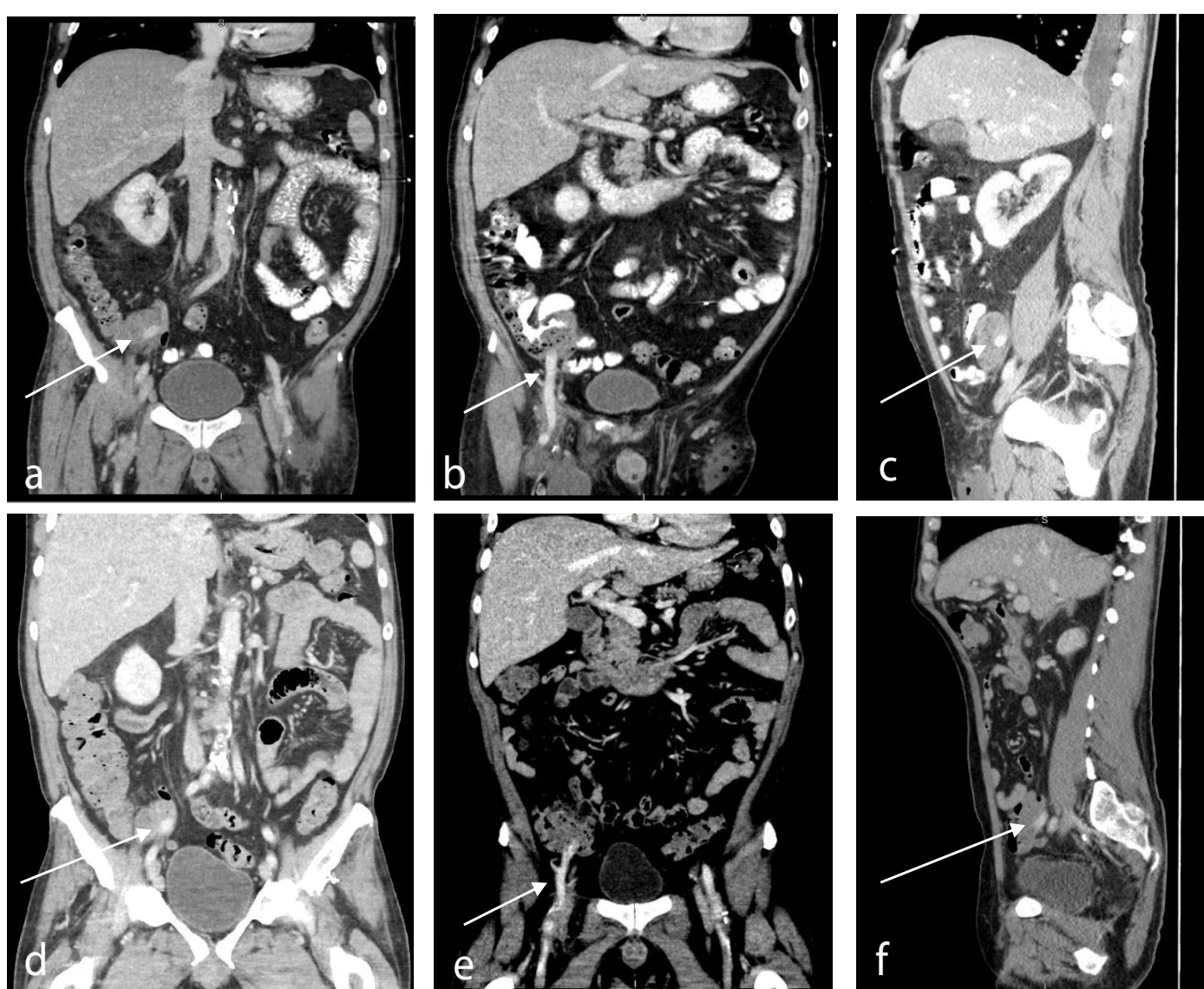

Figure 3 Right limb of aortobifemoral bypass graft (white arrows) traversing the cecum 2 weeks after the initial operation $(a-c)$, and 10 weeks after the initial operation $(d-f)$. Notice the relative cachexia at 10 weeks post-operatively.
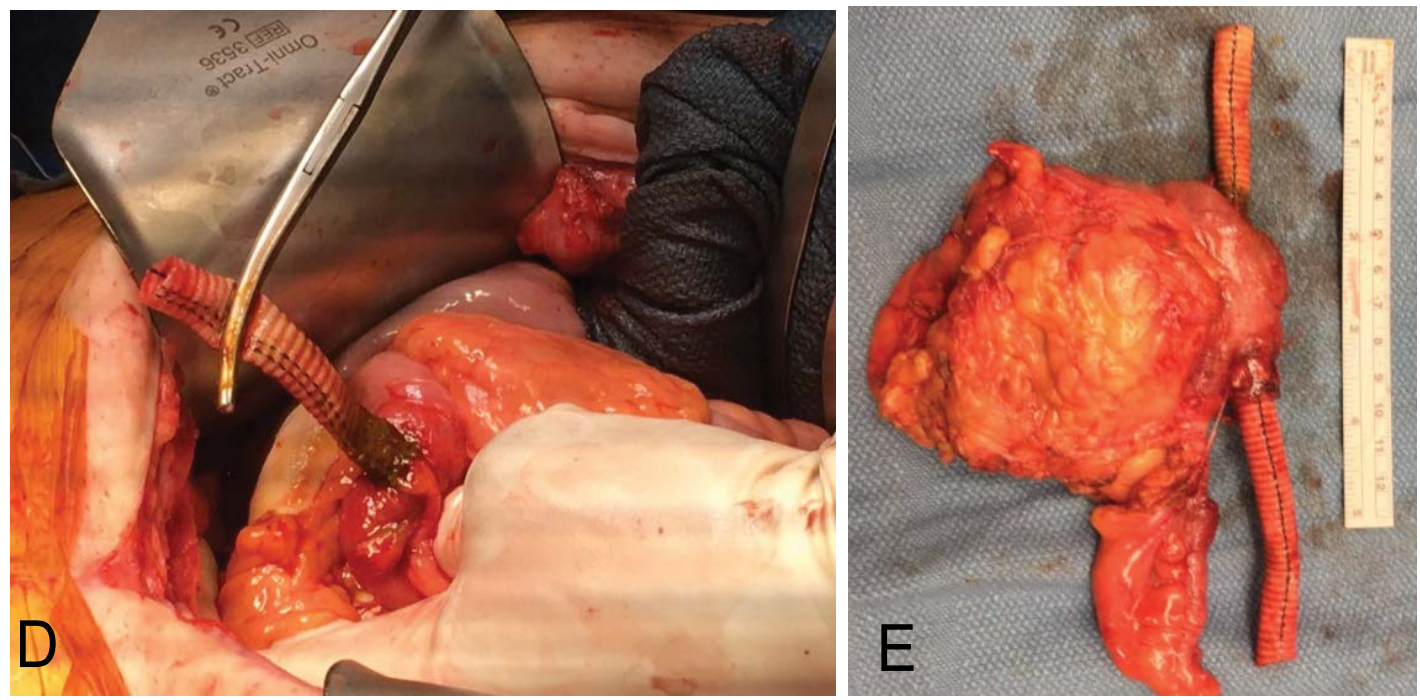

Figure 4 (a) Graft explantation surgery with feet to the left and head to the right; (b) cecum penetrated by graft, with the appendix just lateral to the graft at the bottom of picture. 
course was complicated by right lower extremity ischemia, treated with mid-superficial femoral artery to distal posterior tibial bypass with ipsilateral reversed saphenous vein graft. The postoperative course was also notable for fungal chorioretinitis. Interestingly, the patient's Hemoglobin A1c was measured approximately one month after graft explantation, and had decreased from $12.5 \%$ to $6.3 \%$. The remainder of the laboratory evaluation was unremarkable. The patient was discharged with six weeks of IV meropenem, as well as oral fluconazole and ciprofloxacin, and may require lifelong suppressive antibiotics.

\section{Discussion}

\section{Incidence}

Aortoiliac and aortofemoral revascularization may be performed for either aneurysmal disease or aortoiliac occlusive disease. Since the first endovascular repair of an abdominal aortic aneurysm by Dr. J.C Parodi in 1991, endovascular approaches for aortic surgery have become increasingly common [7-10]. There has been an $850 \%$ increase in iliac artery angioplasty and stenting from 1996-2000 in the Nationwide Inpatient Sample (NIS), while open operations declined by $15 \%$ over the same period [11]. A review of Medicare patients from 1995-2008 confirms this statistic, with endovascular repairs surpassing open repairs of abdominal aortic aneurysms in 2003 [9]. Due to the relative infrequency of open abdominal aortic surgery, surgeon volume has become a significant predictor of in-hospital mortality $[6,9]$. Furthermore, complex aortic anatomy is less amenable to endovascular repair, so while the relative number of open surgeries is decreasing, the complexity is increasing [7]. The current endo first era calls into question surgeon training and experience for such complex open aortic procedures.

The incidence of aortic graft infection after open and endovascular aortic surgery is low, at $0.5-6 \%$, but carries a mortality that may be as high as $88 \%[1,12-16]$. Vogel and colleagues sought to investigate the incidence of aortic graft infections using data collected from all public and private hospitals in the state of Washington between 1987 and 2005. Among 13,902 patients, the rate of graft infection within two years was similar in open versus endovascular procedures $(0.2 \%$ vs. $0.2 \%, p=0.8)$, as well as elective versus non-elective cases $(0.2 \%$ vs. $0.2 \%, p=0.6)$ [13].

Factors other than surgeon experience may influence the rate of morbidity and mortality after aortoiliac revascularization. In their retrospective review, Vogel and colleagues found that patients with perioperative bloodstream septicemia and surgical site infections were at significantly increased risk for developing AGI than those without such infections $(0.93 \%$ vs. $0.18 \%, p=0.014$; $1.61 \%$ vs. $0.19 \%, p=0.01$ ), with the highest risk during the first postoperative year [13]. While Case 1 of this series did not exhibit stigmata of infection, Case 2 clearly had ongoing septicemia that resulted from the transcolonic placement of the aortobifemoral bypass graft.

While the incidence of primary graft infection is low, iatrogenic misplacement of an aortic graft leading to infection is an exceedingly rare occurrence, with only a handful of cases in the literature. Marrocco-Trischitta and colleagues describe a patient who presented with AGI ten months after the index surgery [17]. The patient suffered from Pseudomonas aeruginosa bacteremia two months postoperatively, but was not septic at his later presentation with AGI. Transcolonic placement of the graft was confirmed on CT-angiography (CT-A) and colonoscopy. The patient was taken for staged extra-anatomic bypass and resection of the sigmoid colon and left limb of the aortobifemoral graft limb en bloc, and recovered appropriately [17]. In addition to this case, aortic grafts have erroneously been placed through the bladder [18-20]. In a case report by Finter et al., CT-A and cystoscopy confirmed transvesicular placement of the transobturator aortofemoral bypass graft in a patient who presented with asymptomatic microhematuria [18]. Despite the morbidity and mortality of this complication, these cases presented many months after the index operation, and no patient was overtly septic at presentation.

\section{Diagnosis}

The cases discussed here demonstrate two drastically different presentations of aortic graft infection, both due to similar technical errors. Case 1 is a classic presentation of indolent graft infection, while Case 2 presented more acutely with sepsis secondary to virulent Gram negative organisms. It is unclear if the aortobifemoral grafts were misdirected through the colon without recognition, or less likely, if the grafts eroded into the colon. The patients ultimately recovered from their illnesses when the infected grafts were removed and vascular perfusion was restored by extra-anatomic means. The diagnosis for the patient in the first case was expeditious; however, the diagnosis for the patient in Case 2 may possibly have been made earlier with a higher index of suspicion. The Management of Aortic Graft Infection Collaboration (MAGIC) proposed guidelines for the diagnosis of AGI in 2016, based on major and minor clinical, radiologic, and laboratory findings (Table 2) [12].

Using the MAGIC criteria, an AGI is diagnosed when it meets either one major criterion, or minor criteria from two of the three categories [12]. By these guidelines, Case 1 fulfilled major clinical, radiologic, and laboratory criteria at presentation six months postoperatively. Imaging demonstrated perigraft fluid and gas, and the patient was managed appropriately with broad-spectrum antibiotics and prompt operative bypass and graft explantation. In contrast, the patient in Case 2 did not fulfill any major criteria of AGI at presentation two weeks postoperatively. The presence of Gram negative organisms on blood culture was presumed to be secondary to his pneumonia. However, in communityacquired pneumonia, Gram negative organisms only account for a minority (2-10\%) of cases [21]. While this is not technically a major criterion of the MAGIC guidelines, given the new aortic prosthesis, an alternative source for the bacteremia should have been investigated. Finally, at 10 weeks postoperatively, Case 2 fulfilled major surgical and laboratory criteria, as well as several minor criteria for aortic graft infection, and was then treated appropriately [21].

Early AGIs include those diagnosed within four weeks of the index operation and tend to present with more systemic 
Table 2 Major and Minor Criteria for diagnosis of Aortic Graft Infection. CT=computed tomography; FDG=fluorodeoxyglucose; PET=positron emission tomography; $\mathrm{ESR}=$ erythrocyte sedimentation rate; $\mathrm{CRP}=\mathrm{C}$-reactive protein. (Adapted from Lyons et al.) [12].

\begin{tabular}{|c|c|c|c|}
\hline & Clinical / Surgical & Radiology & Laboratory \\
\hline $\begin{array}{l}\text { M a j o r } \\
\text { Criteria }\end{array}$ & $\begin{array}{l}\text { - Pus (confirmed by microscopy) } \\
\text { around graft or in aneurysm sac at } \\
\text { surgery } \\
\text { - Open wound with exposed graft or } \\
\text { communicating sinus } \\
\text { - Fistula development e.g. aorto- } \\
\text { enteric or aorto-bronchial } \\
\text { - Graft insertion in an infected site e.g. } \\
\text { fistula, mycotic aneurysm or infected } \\
\text { pseudoaneurysm }\end{array}$ & $\begin{array}{l}\text { - Peri-graft fluid on } \mathrm{CT} \geq 3 \text { months } \\
\text { after insertion } \\
\text { - } \\
\text { Peri-graft gas on CT scan } \geq 7 \text { weeks } \\
\text { after insertion } \\
\text { - Increase in peri-graft gas volume } \\
\text { demonstrated on serial imaging }\end{array}$ & $\begin{array}{l}\text { - Organisms recovered from an } \\
\text { explanted graft } \\
\text { - Organisms recovered from an intra- } \\
\text { operative specimen } \\
\text { - Organisms recovered from a } \\
\text { percutaneous, radiologically-guided } \\
\text { aspirate of peri-graft fluid }\end{array}$ \\
\hline $\begin{array}{l}\text { M i n o r } \\
\text { Criteria }\end{array}$ & $\begin{array}{l}\text { - Localized clinical features of AGI } \\
\text { e.g. erythema, warmth, swelling, } \\
\text { purulent discharge, pain } \\
\text { - Fever } \geq 38^{\circ} \mathrm{C} \text { with } \mathrm{AGI} \text { as most likely } \\
\text { cause }\end{array}$ & $\begin{array}{l}\text { Other e.g. suspicious peri- } \\
\text { graft gas/fluid/soft tissue } \\
\text { inflammation; aneurysm expansion; } \\
\text { pseudoaneurysm formation; focal } \\
\text { bowel wall thickening; discitis/ } \\
\text { osteomyelitis; suspicious metabolic } \\
\text { activity on FDG PET/CT; radiolabeled } \\
\text { leukocyte uptake }\end{array}$ & $\begin{array}{l}\text { - Blood culture(s) positive and no } \\
\text { apparent source except AGI } \\
\text { - Abnormally elevated inflammatory } \\
\text { markers with AGI as most likely case } \\
\text { e.g. ESR, CRP, white cell count }\end{array}$ \\
\hline
\end{tabular}

symptoms, such as fever, malaise, leukocytosis, and elevated inflammatory markers such as ESR and CRP [1]. This is true of Case 2, who described symptoms within two weeks of his initial operation. AGIs that occur greater than four weeks after the index operation tend to present with fewer systemic signs, as seen in Case 1 presented here. Blood cultures are positive at presentation in approximately $50-75 \%$ of all patients, regardless of timing of presentation. Commonly isolated organisms include Staphylococcus aureus and coagulase-negative Staphylococcus [1].

Though the second case presented here ultimately had an acceptable clinical outcome, earlier diagnosis of an AGI may have avoided significant morbidity. Two weeks after initial revascularization, the patient was diagnosed with Klebsiella pneumonia and Enterococcus bacteremia, and imaging was notable for perigraft fluid and gas. Bacteremia and the presence of a prosthetic graft should have raised suspicion, or at least warranted close monitoring for aortic graft infection, despite the concurrent pneumonia. Furthermore, the patient's preoperative osteomyelitis and need for continuous suppressive antibiotics should theoretically eradicate most infectious sources. Lastly, and perhaps most importantly, Gram negative community-acquired pneumonia in a patient without a history of an aspiration event or prolonged intubation should raise the question of an alternate source for the bacteremia.

\section{Radiologic tests}

Given the rarity of this complication, the ideal diagnostic test for aortic graft infection is unknown. In the cases presented here, due to the transcolonic placement of the aortic grafts, colonoscopy may have demonstrated the grafts traversing the colon. Marrocco-Trischitta and colleagues clearly identified a limb of an aortic bypass graft in the sigmoid colon on colonoscopy, and the transvesicular graft identified by Finter et al. was similarly seen on cystoscopy $[17,18]$. Additionally, CT scanning in our patients demonstrated perigraft fluid and gas. Due to the timing of presentation in Case 1, this was indicative of aortic graft infection by the MAGIC guidelines [12]. However, the second case presented much earlier, and thus the CT findings were interpreted as normal postoperative changes. While CT scanning has acceptable sensitivity (94-96\%) and specificity (85-90\%) for detecting prosthetic graft infections, other imaging modalities may be warranted, especially when the diagnosis of aortic graft infection is in question [1,22-25].

Radiolabeled leukocyte scanning has a sensitivity and specificity around $90 \%$ for aortic graft infection, but may be less useful in the acute setting, when a postoperative inflammatory state is expected [25]. Furthermore, leukocyte labelling and migration may take up to $24 \mathrm{~h}$ [26]. Positron emission tomography with [18] F-fluorodeoxyglucose (FDG-PET) has shown promise in the diagnosis of aortoenteric fistulae, and may represent a relatively fast, high-resolution method to detect aortic graft infections [26]. Randomized controlled trials may be necessary to determine the sensitivity and specificity of FDG-PET in the diagnosis of aortic graft infection. CT-Angiography was not used in either of the patients here, and its use in this instance is not well represented in the literature. However, Marrocco-Trischitta and colleagues were able to clearly identify an aortic bypass graft limb traversing the sigmoid colon in their case report [17]. This modality may have led to earlier diagnosis of aortic graft misplacement in the second case presented here.

\section{Treatment and Outcomes}

Definitive treatment of aortic graft infection includes broadspectrum antibiotics and removal of the infected graft with revascularization. Select patients may undergo non-operative management, but this also carries a high risk of mortality given inadequate source control. In patients with multiple comorbidities or those with anatomically unfavorable grafts, however, nonoperative management may be the best option. Conservative treatment may be undertaken in one of three ways: using longterm IV antibiotics, fluid aspiration and IV antibiotics, or surgical drainage and IV antibiotics [27]. These options potentially avoid 
reopening the abdomen, as well as the morbidity of prolonged general anesthesia. However, non-operative management must be carefully considered and its risks and benefits thoroughly discussed with the patient.

The gold-standard treatment for aortic graft infections is explantation of the infected graft, debridement of infected tissue, and revascularization, which was performed successfully in both patients presented here. In the setting of infection, surgical explantation carries a mortality of $18-30 \%$ [12]. Revascularization is performed via extra-anatomic routes, however, in situ revascularization with autologous femoral vein or rifampinsoaked grafts is another viable option [14,28]. Regardless of the method of revascularization, expeditious diagnosis and treatment is paramount to patient survival.

\section{Antibiotic Bowel Preparation}

It has been well-established that a combination of oral antibiotic bowel preparation and systemic preoperative antibiotics decrease the risk of infectious complications after elective colon surgery [29-31]. Oral antibiotics such as neomycin are chosen due to their coverage of enteric bacteria, as well as their poor absorption and resultant high concentration within the bowel lumen [30]. The patient in Case 1 received both antibiotic and mechanical bowel preparation and intraoperative graft cultures demonstrated commensal bacteria only. It is possible that more virulent organisms may have been recovered had the patient not received an antibiotic bowel preparation. However, the patient in Case 2 did not receive any antibiotic bowel preparation, and virulent organisms were recovered from the intraoperative specimens. Interestingly, these organisms were isolated from the broth only, which may be a function of the patient's continuous systemic antibiotics. The combination of systemic and oral antibiotics has proven to be more efficacious in reducing infectious complications, as in Case 1, than either antibiotic regimen alone [32-36].

One must also consider the micro-environment of the colon in which the grafts were found. Bacteria that are adherent to the mucosa may differ from populations that exist freely within the lumen, which may be especially important in the case of a foreign body that penetrates the colon [37]. Groner and colleagues were the first to demonstrate that oral antibiotic preparation with neomycin and erythromycin decreased bacteria specifically associated with the mucosa of the colon. This is due to the poor systemic absorption of these antibiotics and high intraluminal concentrations [37]. It is plausible that the neomycin bowel preparation in Case 1 led to decreased mucosa-associated bacteria, as demonstrated by the intraoperative cultures.

\section{Glycosylated Hemoglobin}

The drastic decrease in glycosylated hemoglobin (HbA1c) from $12.5 \%$ to $6.3 \%$ in Case 2 was an unexpected finding. While a decrease in $\mathrm{HbA} 1 \mathrm{C}$ is expected particularly in obesity surgery, in this case it may represent the rapid and dramatic resolution of this patient's catabolic state after surgical intervention. It is unclear if this hyperglycemia preceded the patient's toe osteomyelitis or if this infection initiated a stress-mediated hyperglycemic response. Stress hyperglycemia can be a transient finding in hospitalized or ill patients, and is categorized by patients with and without evidence of preexisting diabetes [38]. Patients with newly diagnosed hyperglycemia are more likely to be admitted to the ICU with critical illness, experience longer hospital stays, and are less likely to be discharged home [38-40]. Our patient did carry a previous diagnosis of $\mathrm{DM} 2$, but had a history of poor glycemic control.

Standard glucose control while hospitalized is associated with reduced mortality in critically ill patients [41-44]. In an observational study of nearly 2,300 medical and surgical patients in a major tertiary care center in Australia, patients without a history of diabetes who experienced hyperglycemia had worse outcomes than those with a history of diabetes. The authors suggest that baseline hyperglycemia may be protective of stress hyperglycemia, possibly due to down-regulation of glucose transporters [40].

Two large randomized trials investigated the difference between intensive and standard glycemic control for patients with DM2 [45-47]. The Action to Control Cardiovascular Risk in Diabetes (ACCORD) trial sought to detect a difference between a goal $\mathrm{HbA} 1 \mathrm{c}$ of $<6.0 \%$ versus a goal $\mathrm{HbA} 1 \mathrm{c}$ of $7.0-7.9 \%$. The trial was terminated early due to an unacceptably increased risk of mortality in the intense glycemic control ( $\mathrm{HbA} 1 \mathrm{c}<6.0 \%)$ group [46]. In contrast, the Action in Diabetes and Vascular Disease: Preterax and Diamicron Modified Release Controlled Evaluation (ADVANCE) trial found improved blood pressure control, fewer microvascular consequences (such as nephropathy and retinopathy), and no change in mortality between the intensive glycemic control group (goal $\mathrm{HbA} 1 \mathrm{c} \leq 6.5 \%$ ) and the standard glycemic control group [47].

To the best of our knowledge, there are no reports of decreases in HbA1C as significant or as quickly as the patient in Case 2. Remission of DM2 after bariatric surgery may occur in up to three-fourths of these patients, but this measurement is usually obtained one year post-operatively, and represents an absolute decrease in $\mathrm{HbA1c}$ of approximately 1-3\% [48-51]. It is plausible that our patient actually had moderate glucose control prior to presentation, and the severity and longevity of his infections may have contributed to his stress hyperglycemia and subsequent complications. The last measured $\mathrm{HbA} 1 \mathrm{c}$ was $8.0 \%$, approximately six years prior to presentation. We suspect that the resolution of his infections, combined with regular endocrinology follow-up, contributed to the drastic decrease in $\mathrm{HbA} 1 \mathrm{c}[52,53]$.

\section{Conclusion}

We have presented two cases of iatrogenic misplacement of an aortic bypass graft through the colon. Interestingly, these cases had vastly different presentations, though the intraoperative findings were similar. Case 1 presented nearly six months after his aortobifemoral bypass surgery, and had no evidence of bacteremia. Graft cultures from this procedure grew indolent skin flora, which is common for this complication 
and may be attributable to the antibiotic bowel preparation. Case 2, on the other hand, had bacteremia within two weeks of the index operation, but was not diagnosed until nearly ten weeks postoperatively. The patient presented with more severe systemic symptoms, and graft cultures grew bowel flora, despite concurrent antibiotic treatment for osteomyelitis and

\section{References}

1 Schurink GW, Peppelenbosch N, Mees B, Jacobs MJ (2016) Diagnostic algorithms and treatment strategies in primary aortic and aortic graft infections. J Cardiovasc Surg 57: 224-232.

2 de Donato G, Setacci F, Galzerano G (2014) Prosthesis infection: prevention and treatment. J Cardiovasc Surg 55: 779-792.

3 Dua A, Koprowski S, Upchurch G, Lee CJ, Desai SS (2017) Progressive shortfall in open aneurysm experience for vascular surgery trainees with the impact of fenestrated and branched endovascular technology. J Vasc Surg 65: 257-261.

4 Chao CT, Liao CH, Lai CC, Hsueh PR (2011) Liver abscess due to Actinomyces odontolyticus in an immunocompetent patient. Infection 39: 77-79.

5 Junckerstorff RK, Robinson JO, Murray RJ (2014) Invasive Streptococcus anginosus group infection-does the species predict the outcome?. Int J Infect Dis 18: 38-40.

6 Rupp ME (2014) Clinical characteristics of infections in humans due to Staphylococcus epidermidis. Methods Mol Biol 1106: 1-16.

7 Aziz A, Sicard GA (2013) Surgical management of abdominal aortic aneurysms: A lost art? Prog Cardiovascular Dis 56: 13-18.

8 Parodi JC, Palmaz JC, Barone HD (1991) Transfemoral intraluminal graft implantation for abdominal aortic aneurysms. Ann Vasc Surg 5: 491-499.

9 Sachs T, Schermerhorn M, Pomposelli F, Cotterill P, O'Malley J, et al. (2011) Resident and fellow experiences after the introduction of endovascular aneurysm repair for abdominal aortic aneurysm. J Vasc Surg 54: 881-888.

10 McPhee JT, Robinson WP, Eslami MH, Arous EJ, Messina LM, et al. (2011) Surgeon case volume, not institution case volume, is the primary determinant of in-hospital mortality after elective open abdominal aortic aneurysm repair. J Vasc Surg 53: 591-599.

11 Upchurch GR, Dimick JB, Wainess RM (2004) Diffusion of new technology in health care: the case of aorto-iliac occlusive disease. Surgery 136: 812-818.

12 Lyons OT, Baguneid M, Barwick TD (2016) Diagnosis of Aortic Graft Infection: A Case Definition by the Management of Aortic Graft Infection Collaboration (MAGIC). Eur J Vasc Endovasc Surg 52: 758-763.

13 Vogel TR, Symons R, Flum DR (2008) The incidence and factors associated with graft infection after aortic aneurysm repair. J Vasc Surg 47: 264-269.

14 Garot M, Delannoy PY, Meybeck A (2014) Intra-abdominal aortic graft infection: prognostic factors associated with in-hospital mortality. BMC Infect Dis 14: 215.

15 Saleem BR, Meerwaldt R, Tielliu IF, Verhoeven EL, van den Dungen $\mathrm{JJ}$, et al. (2010) Conservative treatment of vascular prosthetic graft infection is associated with high mortality. Am J Surg 200: 47-52. pneumonia. A high index of suspicion was absolutely imperative to decrease morbidity for both patients presented here. Once diagnosed, appropriate treatment was initiation with broadspectrum antibiotics, revascularization, and graft explantation, which enabled limb preservation, and more importantly, survival for both patients.

16 Clair DG, Beach JM (2015) Strategies for managing aortoiliac occlusions: access, treatment and outcomes. Expert Rec Cardiovasc Ther 13: 551-563.

17 Marrocco-Trischitta MM, Marone EM, Kahlberg A, Tshomba Y, Setacci $\mathrm{F}$, et al. (2008) latrogenic sigmoid perforation by aortobifemoral left graft limb. Surgery 144: 103-104.

18 Finter F, Kufer R, Simon J, Volkmer BG (2008) Transvesical defect of a transobturator aortofemoral bypass. Urologe 47: 1481-1482.

19 Sheiner N, Sigman H, Stigman A (1969) An unusual complication of obturator foramen arterial bypass. J Cardiovasc Surg 10: 324-328.

20 Hacker A, Uysal Z, Badawi K (2005) Foreign body in the urinary bladder after vascular surgery. Akt Urol 36: 249-251.

21 Mandell G, Douglas R (2015) Acute Pneumonia. In: J Bennett, R Dolin, M Blaser, eds. Mandell, Douglas, and Bennett's principles and practice of infectious diseases. ( $\left.8^{\text {th }} E d n\right)$. Elsevier/Saunders, Philadelphia, pp: 823-846.

22 Gardet E, Addas R, Monteil J, Le Guyader A (2010) Comparison of detection of F-18 fluorodeoxyglucose positron emission tomography and $99 \mathrm{mTc}$-hexamethylpropylene amine oxime labelled leukocyte scintigraphy for an aortic graft infection. Interact Cardiovasc Thorac Surg 10: 142-143.

23 Lauwers P, Van den Broeck S, Carp L, Hendriks J, Van Schil P, et al. (2007) The use of positron emission tomography with (18) F-fluorodeoxyglucose for the diagnosis of vascular graft infection. Angiology 58: 717-724.

24 Low RN, Wall SD, Jeffrey RB, Sollitto RA, Reilly LM, et al. (1990) Aortoenteric fistula and perigraft infection: evaluation with $\mathrm{CT}$. Radiology 175: 157-162.

25 Shahidi S, Eskil A, Lundof E, Klaerke A, Jensen BS (2007) Detection of abdominal aortic graft infection: comparison of magnetic resonance imaging and indium-labeled white blood cell scanning. Ann Vasc Surg 21: 586-592.

26 Krupnick AS, Lombardi JV, Engels FH (2003) 18-fluorodeoxyglucose positron emission tomography as a novel imaging tool for the diagnosis of aortoenteric fistula and aortic graft infection--a case report. Vasc Endovascular Surg 37: 363-366.

27 Lawrence P (2011) Conservative treatment of aortic graft infection. Semin Vasc Surg 24: 199-204.

28 Pupka A, Skora J, Janczak D, Plonek T, Marczak J, et al. (2011) In situ revascularisation with silver-coated polyester prostheses and arterial homografts in patients with aortic graft infection-a prospective, comparative, single-centre study. Eur J Vasc Endovasc Surg 41: 61-67.

29 Englesbe MJ, Brooks L, Kubus J (2010) A Statewide Assessment of Surgical Site Infection Following Colectomy: The Role of Oral Antibiotics. Annals of surgery. 252: 514-520.

30 Fry DE (2011) Colon preparation and surgical site infection. Am J Surg 202: $225-232$ 
31 Cannon JA, Altom LK, Deierhoi RJ (2012) Preoperative oral antibiotics reduce surgical site infection following elective colorectal resections. Dis Colon Rectum 55: 1160-1166.

32 Bellows CF, Mills KT, Kelly TN, Gagliardi G (2011) Combination of oral non-absorbable and intravenous antibiotics versus intravenous antibiotics alone in the prevention of surgical site infections after colorectal surgery: a meta-analysis of randomized controlled trials. Tech Coloproctology 15: 385-395.

33 Lazorthes F, Legrand G, Monrozies X (1982) Comparison between oral and systemic antibiotics and their combined use for the prevention of complications in colorectal surgery. Dis Colon rectum 25: 309-311.

34 Lewis RT (2002) Oral versus systemic antibiotic prophylaxis in elective colon surgery: a randomized study and meta-analysis send a message from the 1990s. Can J Surg J Can Chir 45: 173-180.

35 Nelson RL, Gladman E, Barbateskovic M (2014) Antimicrobial prophylaxis for colorectal surgery. Cochrane Database Syst Rev 5: CD00118.

36 Koullouros M, Khan N, Aly EH (2017) The role of oral antibiotics prophylaxis in prevention of surgical site infection in colorectal surgery. Int J Colorectal Dis 32: 1-18.

37 Groner JI, Edmiston CE, Krepel CJ, Telford GL, Condon RE (1989) The efficacy of oral antimicrobials in reducing aerobic and anaerobic colonic mucosal flora. Arch Surg 124: 281-284.

38 Dungan KM, Braithwaite SS, Preiser JC (2009) Stress hyperglycaemia. Lancet 373: 1798-1807.

39 Umpierrez GE, Isaacs SD, Bazargan N, You X, Thaler LT, et al. (2002) Hyperglycemia: An Independent Marker of In-Hospital Mortality in Patients with Undiagnosed Diabetes. J Clin Endocrinol Metab 87: 978-982.

40 Roberts GW, Quinn SJ, Valentine N (2015) Relative Hyperglycemia, a Marker of Critical Illness: Introducing the Stress Hyperglycemia Ratio. J Clin Endocrinol Metab 100: 4490-4497.

41 The NICE-SUGAR Study Investigators (2009) Intensive versus conventional glucose control in critically ill patients. N Engl J Med 360: 1283-1297.

42 Vriesendorp TM, Morelis QJ, DeVries JH, Legemate DA, Hoekstra JBL (2004) Early Post-operative Glucose Levels are an Independent
Risk Factor for Infection after Peripheral Vascular Surgery. A Retrospective Study. Eur J Vasc Endovasc Surg 28: 520-525.

43 Moghissi ES, Korytkowski MT, DiNardo M (2009) American Association of Clinical Endocrinologists and American Diabetes Association Consensus Statement on Inpatient Glycemic Control. Diabetes Care. 32: 1119-1131.

44 The NICE-SUGAR Study Investigators (2015) Australian and New Zealand Intensive Care Society Clinical Trials Group and the Canadian Critical Care Trials Group. Intensive Care Med 41: 1037-1047.

45 Dluhy RG, McMahon GT (2008) Intensive Glycemic Control in the ACCORD and ADVANCE Trials. New Engl J Medicine 358: 2630-2633.

46 The Action to Control Cardiovascular Risk in Diabetes Study Group (2008) Effects of Intensive Glucose Lowering in Type 2 Diabetes. New Eng J Med 358: 2545-2559.

47 The Advance Collaborative Group (2008) Intensive Blood Glucose Control and Vascular Outcomes in Patients with Type 2 Diabetes. New Eng J Med 358: 2560-2572.

48 Liang Z, Wu Q, Chen B, Yu P, Zhao H, et al. (2013) Effect of laparoscopic Roux-en- $Y$ gastric bypass surgery on type 2 diabetes mellitus with hypertension: a randomized controlled trial. Diabetes Res Clin Pract 101: 50-56.

49 Dixon JB, O Brien PE, Playfair J (2008) Adjustable gastric banding and conventional therapy for type 2 diabetes: a randomized controlled trial. JAMA 299: 316-323.

50 Mingrone G, Panunzi S, De Gaetano F (2012) Bariatric surgery versus conventional medical therapy for type 2 diabetes. N Engl J Med 366: 1577-1585.

51 Lee WJ, Hur KY, Lakadawala M, Kasama K, Wong SK, et al. Gastrointestinal metabolic surgery for the treatment of diabetic patients: a multi-institutional international study. J Gastrointest Surg 16: 45-51.

52 Indes JE, Pfaff MJ, Farrokhyar F, Brown H, Hashim P, et al. (2013) Clinical outcomes of 5358 patients undergoing direct open bypass or endovascular treatment for aortoiliac occlusive disease: a systematic review and meta-analysis. J Endovasc Ther 20: 443-455.

53 De Rubertis BG, Faries PL, McKinsey JF (2007) Shifting Paradigms in the Treatment of Lower Extremity Vascular Disease: A Report of 1000 Percutaneous Interventions. Ann of Sur 246: 415-424. 